\title{
A POLÍTICA NO TEMPO: A ENCENAÇÃOO DA DIALÉTICA
}

Maria de Lourdes Borges ${ }^{\star *}$

SÍNTESE - Neste artigo pretendo mostrar que o desenvolvimento temporal da política na história mundial deve ser considerado como uma encenação da dialética hegeliana. Encenação deve ser aqui tomado como uma apresentação na efetividade de um texto pressuposto. Tal texto é a Ciência da Lógica. Minha intenção è mostrar a utilização, não deste texto na sua totalidade, mas de algumas seqüências preferenciais da lógica. Tal será mostrado: 1) na figura do senhor/servo; 2) na relação eticidade e moralidade. Neste segundo momento, procurarei mostrar como a política e seu julgamento encenam essas categorias. Por fim, indicarei em que medida a idéia de encenação resolve algumas aporias referentes a necessidade e acaso da filosofia hegeliana.

PALAVRAS-CHAVE - Hegel, Dialética, encenaÇão, Politica.
ABSTRACT - In this article I intend to show that the temporary development of the politics in the world history should be considered as an setting (scenery) of the Hegel's dialectic. Setting (scene, scenery) should be taken a presentation here in the effectiveness of a text presupposition. Such text is the Science of Logic. My intent is to show the use, not of this text in its totality, but of some preferential sequences of the logic. Such it will be shown: 1) in the illustration of the Sir/ Slave; 2) in the relationship between ethic and morality. On this second moment, I will try to show as the politics and its judgment designate these categories. Finally, I will indicate in that measured the scene like idea maybe solves some problems referring to the need and the of the Hegel's philosophy.

KEY WORDS - Hegel, Dialectic, Setting (Scene, Scenery), Politic.

para Gerald Thomas, der daseiende Widerspruch

\section{1 - A Ciência da Lógica da encenação}

Se, devido principalmente à vulgarização marxista, a dialética hegeliana foi resumida à tríade tese, antítese e síntese, vários comentadores de Hegel na déca-

\footnotetext{
* Abreviaturas da obra de Hegel utilizadas (citadas segundo a edição da Suhrkamp):

Ast - Vorlesungen über die Ästhetik;

Phäno - Die Phänomenologie des Geistes;

RPh - Grundlinien der Philosophie des Rechts;

$P h R$ - Vorlesungen über die Philosophie der Religion;

$P h G$ - Vorlesungen uber die Philosophie der Geschichte;

WL - Wissenschaft der Logik.

** Universidade Federal de Santa Catarina - UFSC.
}

\begin{tabular}{|l|l|l|l|l|l|}
\hline VERITAS & Porto Alegre & v. 43 & $n^{2} 4$ & Dezembro 1998 & p. 1071-1080 \\
\hline
\end{tabular}


da de 80 - principalmente Pierre-Jean Labarrière e Gwendoline Jarkzik - chamaram a atenção para o fato de que não há uma chave universal que abra todas as portas da filosofia hegeliana. Se há uma lógica do mundo natural e do espírito, esta é toda Ciência da Lógica e todas as categorias que ali se encontram.

O mundo espiritual - enquanto mundo das manifestações culturais - seria a encenação das categorias da Ciência da Lógica. Qual o sentido do termo encenação? Tómo de empréstimo da linguagem teatral: há um texto que é anterior à representação e ao qual esta pode ser mais ou menos fiel. Há, todavia, uma diferença entre texto/apresentação inerente ao processo de encenação. É o đuue, voltando ao texto hegeliano, poderia ser chamado de desrazão da exterioridade. A encenação não é o mesmo que o texto, ainda que o texto esteja sempre implícito na encenação.

Parece-me que o termo encenação é capaz de descrever com clareza a relação entre dialética e mundo espiritual, evitando as armadilhas da filosofia hegeliana que nos faz, ou bem considerar a Ciência da Lógica como incompleta ou aberta a modificações - por não se identificar ao mundo espiritual - ou considerar 0 mundo cultural irracional por não seguir nos detalhes o texto da Ciência da Lógica.

Tentarei mostrar, a seguir, não a utilização de toda as categorias da Ciência da Lógica, mas de uma secuuência que é largamente utilizada por Hegel: as determinações da reflexão (identidade, diferença, oposição, contradição e ir ao fundamento) da Lógica da Essência.

\section{1 - O movimento da reflexão}

A Lógica da Essência tem seu movimento principal na reflexão. A reflexão é um movimento interior, um movimento no qual o devir e o passar permanecem em si mesmo. A primeira diferenciação da essência é a aparência, que mantém com esta uma determinação de ser seu negativo. A aparência não é algo de exterior à essência, elas são momentos diferenciados de uma mesma unidade. Aparentemente, não há unidade entre aparência e essência; entretanto, o que se mostra no começo como uma alteridade da aparência com relação à essência, vai se mostrar, na verdade, como uma relação de aiteridade da essência em relação a ela mesma. A aparência não é exterior à essência, é o movimento de exposição do processo de reflexão da essência.

Temos, na lógica da Essência, três tipos reflexão. O primeiro movimento é a reflexão tética, na qual a essência põe a aparência, como negação de si, mas sem consistência própria. A aparência aqui nada mais é do que o outro da essência, sem autonomia própria. O segundo movimento é a reflexão exterior, na qual o que é posto se reveste de uma exterioridade, perdendo, aparentemente, sua origem. $O$ terceiro momento é a reflexão determinante, que constitui a unificação da reflexão tética e da reflexão exterior. Nela, o outro não é, nem uma negação sem nenhuma consistência (reflexão tética), nem um outro absolutamente exterior (reflexão exterior). O ser-posto, constituído pela reflexão determinante, através de sua reflexão em si, dá origem às determinações da reflexão: identidade, diferença, oposição, contradição e ir ao fundamento. Após um momento de identidade consigo mesma, 
há uma diferenciação entre dois termos $\mathrm{A}$ e B e uma explicitação destes termos como extremos que entram em contradição. Após, a contradição é dissolvida num processo que dá origem a uma nova identidade.

\section{2 - Fenomenologia e a figura do senhor e escravo}

Como estas estruturas aparecem na obra hegeliana? Iniciarei pela Fenomenologia e sua figura mais conhecida: a figura do senhor e do servo, figura paradigmática na luta pelo reconhecimento.

O primeiro momento do processo fenomenológico é a autoconsciência enquanto ser para si simples, igual a si mesma, que exclui toda alteridade como inessencial. Neste primeiro momento, a autoconsciência não apresenta alteridade externa, nem diferenciação interna. Ela é absoluta identidade a si. No segundo momento, temos duas autoconsciências, uma frente à outra, o que equivale ao momento da diferença, diferença esta que se torna diversidade. Temos aqui dois elementos independentes e indiferentes um em relação ao outro. As duas consciências passam, então, a buscar a exclusão da outra, numa luta de vida e morte, o que equivale ao momento lógico da contradição. Esta contradição será dissolvida apenas pelo seu aprofundamento, o que dará origem a uma nova figura.

Este movimento, que é o movimento lógico da reflexão, e que aparece claramente na figura do senhor e do servo, será amplamente utilizado por Hegel no desenvolvịmento histórico. Analisaremos um momento deste desenvolvimento - a relação entre moralidade e eticidade - a fim de compreendermos de que forma a política pode ser a encenação deste trecho da lógica.

\section{2 - A encenação na política}

O desenvolvimento da idéia da liberdade no tempo apresentará igualmente os momentos das determinações da reflexão. Se tomarmos de um lado, a liberdade como efetivação desta nas instituições sociais e estatais (Eticidade) e liberdade como capacidade de julgamento interior do que é bom (Moralidade), a relação destas duas seguirá o percurso de um primeiro momento de identidade, passando por uma oposição que se dissolverá dando origem a uma novo momento.

O momento da identidade imediata seria apresentado no mundo grego, pois nele, segundo Hegel, as leis da consciência eram as leis da pólis. Antígona e Sócrates eram exemplos desta justiça da subjetividade que não se fazia ainđa presente no mundo grego, o que dará origem a um fio condutor que nos levará ao cristianismo. A análise que Hegel faz de Antígona, tanto na Fenomenologia quanto na Filosofia do Direito, mostra bem este elemento subversivo que esta representava relativamente a este primeiro momento de identidade. Tentemos entender a concepção de Hegel do mundo grego pelo seu avesso, ou seja, a figura de Antígona. Ela é este elemento de diferença que se insinua numa identidade, e que dará origem, posteriormente, a oposição entre moralidade e eticidade. 


\section{1 - A mais profunda solidão interior consigo}

Uma das caracterizações que Hegel faz do sujeito moral nos Princípios da Filosofia do Direito é pensá-lo como essa "mais profunda solidão interior consigo", "o completo retraimento dentro de si". São exatamente estas as características que possibilitam ao sujeito determinar, por si mesmo, o que é justo e bom. Essa determinação, no que toca à Antígona, é apresentada como uma determinação divina, como uma justiça que não é dada pela lei da pólis.

Ao ser interrogada por Creonte se sabia que o edito proibia sua ação, ela responde:

Antígona: Sabia, como ignorá-1o? Era público. ${ }^{1}$

Creonte: E tu ousaste desobedecer as leis?

Neste momento, Antígona explicita a razão de seu ato: não reconhece, nas leis da pólis, o fundamento da justiça, justiça que é dada por outras leis não escritas, que vigem desde sempre:
Antígona; "Mas não foi Zeus quem as proclamou
e a justiça que reside com os deuses
de baixo da terra
não as ditaram entre os homens
e não me parece que tuas
determinações tivessem força para impor aos
mortais até a obrigação de transgredir leis
divinas, não escritas, inevitáveis".

Na fala de Antígona, vêem-se esboçados os princípios dessa autodeterminação do justo e do bom- ainda que ela não apresente seus atos como uma determinação do sujeito moral, mas seguindo uma justiça divina.

Na pergunta de Creonte: "Você ignorava o que a lei prescrevia?" está implicita a idéia de que apenas a ignorância da lei poderia justificar uma ação contrária à lei. Na resposta de Antígona (essas leis não são ditadas pela justiça) vemos que ela desobedece a lei da pólis

1) pois esta não é a medida do justo

2) pois há uma outra medida do justo

3) que essa outra medida do justo não se deixa esgotar na contingência de leis particulares ditadas por um governante

4) que a outra medida do justo está além do tempo,ou seja, é eterna

Ora, poderiamos objetar que Antígona não poderia de forma alguma ser considerada como representante - ainda que representante precoce - da autodeterminação moral, pois ela não afirma que determina por si só o que é justo e bom, mas que representa uma outra ordem, não humana, mas divina.

Tal mediação, de uma ordem divina para destacar a medida universal do justo da sua medida particular e contingente, aparece igualmente na religião cristã: é ao se pensar como pertencente a um outro reino - divino em oposição ao humano que o cristão primitivo dissolve as determinações institucionais e instaura uma

1 As citações serão feitas conforme a edição da Belles Letres. 
nova ordem. Essa dissolução, no caso do cristianismo, atinge as bases do tecido institucional romano, do qual a família é parte essencial. A comunidade cristã impõe-se como a dissolução dos laços familiares. Como prova, Hegel ressalta, nas Lições sobre a Filosofia da História (PhG, p. 393), o que Cristo responde a um homem que quer enterrar seu pai: "Deixe os mortos enterrar seus mortos e sigame".

A lei divina aí não é a lei humana, nem se confunde com a medida do justo dada por nenhuma de suas instituições. Nesse sentido, "a profunda solidão interior consigo mesmo", característica da moralidade subjetiva, expressa-se de forma plena no cristianismo. Em Antígona, o princípio da moralidade subjetiva, ainda que se insurgindo contra a lei da pólis, não o faz em relação aos laços familiares. Por essa razão, Hegel cita Antígona no \& 166 da RPh, dedicado ao primeiro momento da eticidade, seu momento natural, e afirma que ela expressa a lei da substancialidade subjetivà sensivel.

\section{2 - Da identidade à contradição}

$\mathrm{Na}$ discussão inicial entre Antígona e Ismênia, enquanto a primeira reivindica uma justiça da qual ela é representante e que não se deixa expressar puramente nas leis da pólis, Ismênia, ao contrário, abdica de seu dever feminino de fazer valer a lei dos deuses e dos mortos, não porque reconheça a justiça do edito de Creonte, mas porque reconhece o dever de obediência e a impossibilidade - ou a desmedida - de um ação contrária à lei.

Ismênia: (74-76): "mas desobedecer as leis da cidade, não, sou incapaz."

A consciência de representar uma outra lei - a lei da substancialidade subjetiva - se faz notar na resposta que Antígona dá à recusa de Ismênia: "Evoca este pretexto. Eu recobrirei de terra o corpo do meu irmão querido."

A idéia de um crime piedoso marca a conformidade da intenção de Antígona a uma outra ordem que não a ordem constituida pelos governantes. Hegel, no \&166 da RPh, afirma que a Antígona de Sófocles expressa a lei da mulher como "lei da substancialidade subjetiva sensivel", "lei dos antigos, imagem de uma lei eterna que não se sabe quando apareceu". Essa lei eterna está em oposição à lei manifesta, à lei do Estado "uma oposição que é a mais altamente ética e conseqüentemente, a mais altamente trágica, na qual a feminilidade e a masculinidade são individualizadas".

Tal oposição altamente ética e, por essa razão, altamente trágica, na qual o princípio da feminilidade - lei da substancialidade subjetiva sensivel - opõe-se ao princípio da virilidade - lei da objetividade - evidencia-se no diálogo entre Creonte e Antígona, tão logo aquele tenha sido informado do sepultamento de Polinice:

Ao ser indagada se não se envergonhava de ter sepultado e feito os ritos fúnebres a um inimigo da cidade, Antígona responde; alegando sua filiação a um outro princípio de julgamento: "Não há vergonha alguma em honrar aqueles do nosso sangue" (510); "Nasci para partilhar amor, não ódio" (520). Ao que Creonte objetará: "Se tens de amar, então desce, vai para o outro mundo, enquanto eu estivar vivo, não será uma mulher que fará as leis." (600) 
Fica claro aqui a oposição a que Hegel se refere: de um lado a Weiblichkeit, que incarna a legitimidade de um vinculo natural (Polinice e Etéocles têm os mesmos direitos, pois nasceram das mesmas estranhas), ao mesmo tempo em que justifica os sentimentos piedosos (nasci para compartilhar amor, não ódio). De outro lado, a Männlichkeit que simboliza os vinculos da vida substancial real do Estado. Nem morto o inimigo passa a ser amigo - ressalta Creonte. Quem amar um inimigo da pólis deve ir para outro mundo, pois os sentimentos piedosos não devern igualar o que morreu defendendo a cidade ao que morreu destruindo-a.

\section{Uma oposição trágica: a lei da pólis e a lei da familia}

Ainda que Antigona represente o principio de interioridade, de subjetividade exterior sensivel e Creonte, o princípio da exterioridade, sua oposição não seria uma oposição trágica se a primeira não deixasse o espaço próprio reservado a ela na Eticidade grega: a pólis e da familia. Ao comentar essa oposição, na Estética, Hegel a remete a uma outra, a que se instala, na mitologia grega, entre os deuses antigos e os novos deuses. Antígona apresenta-se como aquela que representa a lei dos deuses, mas os deuses por ela venerados são os deuses de baixo, os deuses do Hades, os deuses do sentimento, do amor, do sangue, não os deuses do dia, da vida do Estado e do povo livre a autoconsciente. ${ }^{2}$ Os deuses do Hades, cuja lei Antígona representa, representam a natureza, os deuses da cidade, o mundo político e espiritual. ${ }^{3}$ Esta diferença entre os deuses antigos e os novos deuses é analisada nas Lições sobre a Filosofia da História. ${ }^{4}$ Os primeiros deuses (Urano, Gea, Okeanus, Selene, Hélio) representam as forças naturais, cuja soberania é destruida por Zeus. Essa destruição, por Zeus, da primeira linhagem de deuses significaria a superação da naturalidade pela espiritualidade. Zeus aparece, então, como o representante de uma nova linhagem de deuses, cuja essência é propriamente espiritual; todavia, o elemento natural é conservado e não totalmente suprimido, pois os novos deuses mantêm uma relação com as forças naturais: "Zeus possui seus relâmpagos e suas nuvens, Hera é a produtora do natural, a parteira da vida".

A oposição trágica entre Antígona e Creonte pode ser lida num triplo registro:

1) oposição entre a feminilidade e a virtude

2) oposição entre lei da família e lei da pólis

3) oposição entre deuses antigos (os deuses do Hades) e os novos deuses.

A subjetividade sensivel de Antígona representa uma justiça, cuja esfera própria é a familia e cujo fundamento é dado pelos deuses da primeira linhagem cuja característica é a naturalidade (ligação com a natureza). Por essa razão, ela apela para a vinculação natural existente entre ela e seus dois irmãos, uma justiça do sangue e das entranhas: ela apela ao sentimento do amor e à virtude da piedade. O sensivel, derivado da naturalidade dos deuses que representa, caracteriza a subjetividade de Antígona.

\footnotetext{
Ast, I, 60 .

Mundo espiritual, no sentido que Hegel confere a esta expressão, significa o mundo cultural. $P h G$, p. 330.
} 
É na Fenomenologia do Espírito que Hegel analisa com mais detalhe essa oposição entre, de um lado, a lei humana, lei do homem ou lei do dia e, de outro lado, a lei divina, lei da mulher ou direito da sombra. Vemos que Hegel opõe uma lei do dia a um direito da sombra, o primeiro correspondendo à lei humana e a segunda, à lei dada por Deus, da qual a mulher se faz portadora.

A lei humana é a lei da comunidade. Hegel esclarece o significado comunidade "A comunidade é o espírito que é para si [...] ao se refletir nos indivíduos e que é em si ou que é sustância quando ele os contém em si. Como substância efetiva este espírito é um povo, como consciência efetiva ele é cidadão do povo". 5

A consciência do cidadão e a certeza de si têm no espírito do povo sua essência e sua efetividade, ou seja, o mundo grego não fez ainda esta separação entre, de um lado, a consciência e a certeza de si moral e, de outro, a lei e os costumes constituídos do Estado e da comunidade. Assim a consciência do cidadão só tem efetividade no espírito do seu povo, nơs seus costumes e leis. Mas, a essa potência ética e a essa manifestação à luz do dia da verdade, opõe-se uma outra potência: a lei divina. A lei divina rege uma outra comunidade - uma comunidade ética natural. Nessa caracterização de comunidade ética natural, podemos perceber a mesma dupla significação da subjetividade, representada por Antígona (uma substancialidade subjetiva sensivel). Trata-se, nos dois casos, de uma dupla vinculação: uma relação espiritual e uma relação natural. Essa dualidade é explorada por Hegel ao comentar a significação espiritual dos ritos de sepultamento: o dever do membro da família é não deixar que a morte seja apenas natural, mas restituir, através de um ritual próprio, seu caráter espiritual.

Não é à toa, portanto, que a oposição trágica dessas duas ordens (do dia e da sombra) confrontam-se no ato de sepultamento. O horror que Antígona manifesta a deixar o corpo do irmão insepulto, presa possível de aves carniceiras, revela a necessidade de conferir um caráter espiritual a morte - através da qual o homem reafirma seu caráter racional - ao invés de deixá-lo ser apenas um fato da natureza: "visto que o repouso e a universalidade da essência consciente de si não pertence verdadeiramente à natureza, o sentido da ação é afastar essa aparência de uma tal operação usurpada pela natureza e de restituir a verdade" 6

O sentido ético dos rituais de sepultamento é conferir espiritualidade ao que seria pura desagregação natural do ser singular (pura singularidade); é a relação de parentesco, a relação de sangue, que transforma um movimento natural num movimento da consciência:

"A relação de sangue completa o movimento da consciência , interrompendo a obra da natureza e arrancando-a à destruiçăo; ou ainda, visto que esta destruição, a passagem ao ser puro, é necessária, ela (a família) toma para si a operação da destruição"”

Esta ação (de levar a cabo os ritos de sepultamento) é uma ação ética relativa ao ser singular, enquanto este pertence a uma comunidade natural - ação ética relacionada a um direito divino que se opõe, no caso de Antígona, a um direito

PhE, II, p.

PhE, II, 21

Ibidem, $\mathrm{p}$. 
humano, a um direito que rege a comunidade enquanto corpo político. A comunidade ética natural e a comunidade ético-política não constituiriam, em princípio em esferas antagônicas: seriam apenas esferas distintas. A tragicidade de Antígona mostra-se pela condução da diferença à oposição e contradição. Novamente aqui as determinações da reflexão: Identidade (Identität), diferença (Unterschied), oposição (Gegensatz), contradição (Widerspruch).

Esta contradição é expressa magnificamente pela imagem de Antígona, rumando para a morte em vida. Antígona enuncia um princípio ainda prematuro do seu tempo: a capacidade de por si só, decidir o que é justo e bom. É esse espanto por ver nascer um princípio prematuro, que engendrar tamanha contradição, o que faz recitar o corifeu:

\footnotetext{
"Nem uma doença te atingiu

Nem uma espada te feriu

Tomando tua lei em ti mesmo

Tu desces ao Hades" (820)
}

\section{3 - Da contradição à sua suprassunção numa nova efetividade}

A descida ao Hades de Antígona expressa corretamente o zu Grund gehen hegeliano, um afundar que é, ao mesmo tempo, um ir ao seu próprio fundamento. Vejamos então como, a partir deste afundamento, temos um novo fenômeno (Erscheinug) que dará origem a uma efetividade (Wirklichkeit).

O cristianismo católico realiza o princípio da subjetividade que, filosófica e metaforicamente, havia sido enunciado por Sócrates e Antígona, figuras que representam para Hegel esse ponto de inflexão rumo à interioridade. A inflexão prematura surge num Estado que, não possuindo a potência do estado moderno, mostra - e a tragédia de Antígona é exemplar neste sentido - o preço pago pela enunciação fora do tempo, ou fora da esfera própria, do princípio da subjetividade.

Esse ponto de inflexão do próprio espírito objetivo rumo à interioridade (o afundamento - das essencialidades da reflexão) apresenta-se historicamente como a diferença entre a antigüidade e os tempos modernos: "o direito da particularidade do sujeito a encontrar-se satisfeito ou, o que é o mesmo, o direito da liberdade subjetiva constitui o ponto de inflexão e o ponto central da diferença entre a antigüidade e os tempos modernos" ( $R P h, \S 124)$.

Os tempos modernos trazem consigo a idéia de homem como sujeito moral, para o qual a obrigação não é dada por algo exterior, mas pelo próprio saber interior do que é justo e bom; "essa mais profunda solidão interior consigo" (diese tiefste innerliche Einsamkeit mit sich), "o completo retraimento dentro de si mesmo" (diese durchgängige Zurückgezogenheit in sich selbst) constituem a consciência moral que sabe que seu pensar é o único que obriga ( $R P h \S 136 \mathrm{Zu})$. Tratase de uma capacidade de julgar interior, independente de instituições, que determina, por si mesmo, o que é justo e bom.

Mas é apenas no Estado moderno, obra do penoso trabalho do espirito na história que o filósofo vislumbra a plena realização do universal e a correta administração da coisa pública, ao mesmo tempo que possibilita o desenvolvimento da subjetividade moderna. Os direitos individuais e o exercício da moralidade, não só 
não são tolhidos pela potência do Estado, como só podem-se realizar plenamente nesse: "O princípio dos Estados modernos tem essa força e essa profundeza de deixar o principio da subjetividade realizar-se ao extremo da particularidade pessoal autônoma e, ao mesmo tempo, de reconduzi-la à unidade substancial e assim, de manter essa unidade em si mesmo" (RPh § 260).

O Estado, enquanto realização plena da vida ética pode conter em si o princípio da subjetividade moderna, sem ser destruído por essa; ao contrário, sua potência alimenta-se do exercício individual da autonomia, do julgamento e da participação ativa dos cidadãos. Mas o estado grego não possuía essa força de poder deixar o princípio da subjetividade realizar-se ao extremo da particularidade pessoal autônoma; por essa razão, Antígona deve perecer, pois personifica a radicalização do princípio da subjetividade, ou a sua fuga de uma esfera própria (a família), o que não poderia ser absorvido na bela totalidade ética.

\section{3 - Encenação e temporalidade}

A concepção da Ciência da Lógica enquanto um texto pressuposto nos auxilia a resolver alguns problemas relativos à necessidade e acaso da filosofia hegeliana. Hegel, na suas Lições sobre a Filosofia da História, afirma que o propósito do filósofo é eliminar o acaso:

“A reflexão filosćfica não tem outro fim senão remover o contingente (das Zufällige zu entfernen). A contingência è o mesmo que a necessidade exterior, uma necessidade que deriva de causas que são, elas mesmas, apenas circunstâncias externas" (VG, p. 29; RH, p. 48)

Qual o sentido da eliminação do acaso? Seria exatamente o descobrir dessas categorias que orientam a encenação histórica, expor esse texto implícito - escrito pelo Absoluto - e que serve como base para os eventos do mundo espiritual, compreendido como o mundo político e cultural.

Além de eliminar o acaso, Hegel pretende refazer a teodicéia hegeliana. É o que afirma no início das Lições sobre a Filosofia da História: Hegel, ao iniciar suas Lições sobre a Filosofia da História admite explicitamente que busca inspiração na filosofia de Leibniz, principalmente nos Ensaios de Teodicéia:

\footnotetext{
"Nossa meditação é, nessa medida, uma teodicéia, uma justificação de Deus que Leibniz tentou de forma metafisica, à sua maneira, e com categorias ainda indeterminadas e abstratas; o mal no universo deveria ser compreendido e o espírito que pensa reconciliado com esse mal. De fato, nada nos leva mais a esse conhecimento reconciliador do que a história mundial".(Ph.G, p.28)
}

Qual o sentido de refazer a teodicéia leibniziana em categorias menos abstratas? Conforme bem expressa G. Lebrun, ${ }^{8}$ a teodicéia hegeliana não busca, como as teodicéias ingênuas, encontrar uma justificativa para cada acontecimento. A "verdadeira teodicéia" não precisaria "subjugar a causalidade acidental", ela "não procura transformar o fortuito em significativo, porém mostrar que esse emaranhado confuso produz sentido à medida que vai passando".

8 Lebrun, $O$ avesso da dialética, p. 35. 
A diferença portanto entre Leibniz e Hegel, no que concerne à relação Absoluto - mundo finito é análoga à relação entre uma peça teatral clássica - onde todos as ações e os movimentos dos atores estão previamente marcados - e uma encenação contemporânea, na qual o texto é um fio condutor que serve a várias encenações possiveis. Todavia , isso não pode nos levar a pensar numa abertura à contingência, numa dependência das vontades particulares dos atores/ agentes da história. O espirito do mundo, assim como o encenador contemporâneo, é aquele que antecipa o resultado que deseja... 